See Article page 1 in the September 2020 issue.

\section{Commentary: "Spinoplegia": A new solution for ischemic spinal cord injury?}

\author{
Hamdy Awad, MD, ${ }^{\mathrm{a}}$ and \\ Bryan A. Whitson, MD, $\mathrm{PhD}^{\mathrm{b}}$
}

The history of spinal cord ischemic injury secondary to aortic aneurysm repair dates back to Dr Alexis Carrel's prediction of the complication in 1910. Evidence from the Society of Thoracic Surgeons and Vascular Quality Initiative registry show that this feared complication is still prevalent today. Currently, the only interventions used to prevent or treat this complication are hypothermia, cerebrospinal fluid (CSF) drains, and systemic and spinal cord perfusion pressure management.

Naganuma and colleagues ${ }^{1}$ advent of using nanobubble technology as an adjunct to prevent spinal cord ischemia following crossclamping during aortic aneurysm repair procedures shows promise. Nanobubbles provide an alternative pathway to supply oxygen to the spinal cord that suppresses the inflammatory responses secondary to ischemiareperfusion injury following aortic crossclamping. The question is will this promising technology be transferable from animal models to humans, and what are the potential limitations to this transferability? Naganuma colleagues ${ }^{1}$ suggest potential limitations in their study, but there are more to consider with regard to transferability to humans.

One major limitation in the transferability from the animal models of this study to humans is the difference in spinal cord

From the ${ }^{\mathrm{a} D i v i s i o n}$ of Cardiothoracic Anesthesia, Department of Anesthesia, and ${ }^{\mathrm{b}} \mathrm{Di}$ vision of Cardiac Surgery, Department of Surgery, The Ohio State University Wexner Medical Center, Columbus, Ohio.

This editorial is supported by National Institutes of Health NINDS R21NS113097-01 grant funding to H.A.

Disclosures: B.A.W. is a consultant/speaker for Abbott Laboratories, is a proctor for Medtronic, and serves on the Clinical Events Committee of TransMedics OCS. H.A. reported no conflicts of interest.

The Journal policy requires editors and reviewers to disclose conflicts of interest and to decline handling or reviewing manuscripts for which they may have a conflict of interest. The editors and reviewers of this article have no conflicts of interest.

Received for publication Aug 26, 2020; revisions received Aug 26, 2020; accepted for publication Aug 28, 2020; available ahead of print Oct 20, 2020.

Address for reprints: Bryan A. Whitson, MD, PhD, Section of Thoracic Transplantation and Mechanical Circulatory Support, Division of Cardiac Surgery, Department of Surgery, Ohio State University Medical Center, N-816 Doan Hall, 410 W 10th Ave, Columbus, OH 43210 (E-mail: bryan.whitson@ osumc.edu).

JTCVS Open 2021;5:35-6

2666-2736

Copyright (C) 2020 The Authors. Published by Elsevier Inc. on behalf of The American Association for Thoracic Surgery. This is an open access article under the CC BY-NCND license (http://creativecommons.org/licenses/by-nc-nd/4.0/).

https://doi.org/10.1016/j.xjon.2020.08.019

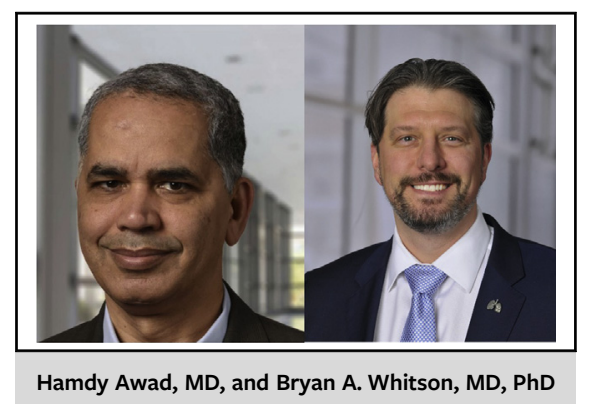

CENTRAL MESSAGE

The creation of nanobubble technology for spinal cord protection is promising in rabbit models and, if proven to be safe and efficacious in humans, will become the standard of care just as CSF drains.

vascular anatomy between small animal models and humans. This differing anatomy may limit the diffusion of nanoparticles deep into the gray matter where interneurons are located, and where our research shows ischemic damage begins. ${ }^{2}$ In addition, the intrathecal space is a closed space and the injection of artificial, oxygenated CSF at a rate of $5 \mathrm{~mL} / \mathrm{h}$ of in rabbit models performed in this study would be equivalent to an injection of $350 \mathrm{~mL} / \mathrm{h}$ in humans. Our preclinical and clinical work has documented spinal cord edema as part of the mechanism of spinal cord ischemic injury. ${ }^{3}$ It is not clear what the impact of large volumes of fluid injection will be on spinal cord edema in humans. Finally, we believe that the mechanism of ischemic spinal cord injury between open and endovascular repair of aortic aneurysms is different. The mechanism of spinal cord damage in open repair is ischemia-reperfusion versus critical permanent hypoperfusion in endovascular repair. In addition, we believe that the location of spinal cord damage in endovascular repair is predominantly located in the white matter, which is consistent with a different mechanism of injury following this surgical technique. ${ }^{4}$ Therefore, we do not know what the impact of nanobubbles will be on spinal cord damage in endovascular repairs, which is the technique used in a majority of aortic aneurysm repairs across the globe. Future studies will tell whether the use of nanobubbles will be effective in preventing spinal cord damage in endovascular aortic aneurysm repairs.

The creation of nanobubble technology from our Japanese colleagues is promising in rabbit models, and we are 
hopeful that it proves to be safe and efficacious in humans following preclinical and clinical phases, and will thus become the standard of care just as CSF drains became the standard of care following Miyamoto and colleagues' ${ }^{5}$ original research published in the Journal of Cardiovascular Surgery in 1960.

\section{References}

1. Naganuma M, Saiki Y, Kanda K, Akiyama M, Adachi O, Horii A, et al. Nanobubble technology to treat spinal cord ischemic injury. J Thorac Cardiovasc Surg Open. 2020;3:1-11.
2. Awad H, Ankeny DP, Guan Z, Wei P, McTigue DM, Popovich PG. A mouse model of ischemic spinal cord injury with delayed paralysis caused by aortic crossclamping. Anesthesiology. 2010;113:880-91.

3. Awad H, Bratasz A, Nuovo G, Burry R, Meng X, Kelani H, et al. MiR-155 deletion reduces ischemia-induced paralysis in an aortic aneurysm repair mouse model: utility of immunohistochemistry and histopathology in understanding etiology of spinal cord paralysis. Ann Diagn Pathol. 2018;36:12-20.

4. Awad H, Ramadan ME, El Sayed HF, Tolpin DA, Tili E, Collard CD. Spinal cord injury after thoracic endovascular aortic aneurysm repair. Can J Anaesth. 2017;64: 1218-35.

5. Miyamoto K, Ueno A, Wada T, Kimoto S. A new and simple method of preventing spinal cord damage following temporary occlusion of the thoracic aorta by draining the cerebrospinal fluid. J Cardiovasc Surg (Torino). 1960;1:188-97. 